\title{
Synoptic Climatology of Weather Parameters Associated With Tropical Cyclone Events In The Coastal Areas of Bay of Bengal
}

Mehnaz Abbasi Badhan

Begum Rokeya University

Murad Ahmed Farukh

Bangladesh Agricultural University

Md. Al-Mussabbir Hossen

Samsung C\&T

Abu Reza Md. Towfiqul Islam ( $\square$ towfiq_dm@brur.ac.bd)

Begum Rokeya University https://orcid.org/0000-0001-5779-1382

\section{Research Article}

Keywords: Sea level pressure, severe cyclone, Geopotential height, PCA, K-mean Clustering, Bangladesh

Posted Date: November 3rd, 2021

DOI: https://doi.org/10.21203/rs.3.rs-954033/v1

License: (9) This work is licensed under a Creative Commons Attribution 4.0 International License. Read Full License 


\section{Abstract}

Tropical cyclones (TCs) are the most devastating weather phenomena that trigger massive loss of property and life in the coastal areas of the Bay of Bengal (BoB). Scientific understanding of TCs occurrence can aid policy-makers and residents in coastal areas to take necessary actions and appropriate planning in advance. In this study, we aimed to examine the possible linkage of weather parameters with deadly 22 TCs events in the BoB from 1975 to 2014 using principal component analysis, K-mean clustering and General circulation model (GCMs). Results showed that among 22 TCs, cluster 1 belongs to $12 \mathrm{TCs}$ which occurred under the same atmospheric situation when the sea level pressure (SLP) was below $990 \mathrm{hPa}$, and the temperature ranged from $300 \mathrm{C}$ to $390 \mathrm{C}$. A deep negative anomaly of SLP and temperature was observed up to $500 \mathrm{hPa}$ levels. In contrast, a negative depression was found at $300 \mathrm{hPa}$ geopotential height (GPH) over the study area. Cluster 2 consisted of 9 TCs when SLP was below $1000 \mathrm{hPa}$, and the average temperature was $33.50 \mathrm{C}$. A strong negative anomaly was noticed when surface level up to $500 \mathrm{hPa} \mathrm{GPH}$, but dramatically this depression was completely absent at $300 \mathrm{hPa}$ geopotential height over the BoB and entire coastal region. Cluster 3 contained only 1 TCs when the atmospheric circumstance was completely diverse, and the SLP was above $1000 \mathrm{hPa}$. The results of the GCM model revealed that the SLP was lower, and the temperature was higher over BoB compared to the North Indian Ocean. We identified the larger depression of SLP and unpredictable temperature anomalies at the upper atmosphere that can trigger an enormous unpredictability throughout the atmospheric level, leading to severe TCs. The outcomes of this study can improve our understanding of weather variables in the upper atmospheric column for forecasting the TCs system more accurately in the future.

\section{Introduction}

Tropical cyclones (TCs) are the utmost damaging and potentially extreme life-threatening weather events in the tropical coastal regions, including Bangladesh (Alam et al. 2003; Parker et al. 2017; Wahiduzzaman et al. 2021a). The TCs are the weather associated disaster over the Bay of Bengal (BoB), which trigger enormous damage to properties and lives in these coastal regions (Paliwal and Patwardhan 2013; Vissa et al. 2013; Balaguru et al. 2014; Rajasekhar et al. 2014; Mohapatra et al. 2014). TCs can cause hazardous effects via heavy winds and floods triggered by related storm surges and heavy precipitation over the BoB (Wahiduzzaman et al., 2020a; b). Although small amount (7\%) of the global TCs frequency occurred in the North Indian Ocean such as Bangladesh, India and Myanmar, the social and economic effects of TCs in the vital region is much higher than those in other TCs region (Wahiduzzaman et al., 2020a). For instance, in 2008, severe cyclone Nargis, more than 38,000 people casualties and a US\$10 billion loss occurred in Bangladesh (Webster 2008). Apart from the deadly costs to human life, TCs pose a considerable monetary risk to the nearby coastal inhabitants (Rumpf et al., 2007). The high fatality in the BoB coastline area is due to the low-lying deltaic topography, landfall, shallow bathymetry level of the continental shelf zone and funnel-shaped shoreline, which creates the region highly susceptible to storm surge induced flooding and direct wind speed (Wahiduzzaman et al. 2021b). Moreover, the residents' high population growth and poor social and economic situation along the BoB coastline also found driving 
factors behind the damages generated by TCs. Thus, a thorough understanding of synoptic climatology of weather parameters associated with TCs over the BoB is highly important (Singh et al., 2012).

Extreme weather events, i.e., severe TCs posed a challenging situation for the scientists, planners, and decision-makers as these TCs events affect society and the eco-environment (Seneviratne et al., 2012). A few studies have been reported that it is challenging to study and forecast these weather extremes because of their nature, rarity and severity; thus, the data are inadequate (Sillmann et al., 2017; Maw and Jinzhong, 2017; Islam et al., 2020; Wahiduzzaman and Yeasmin 2019). Sometimes less noteworthy coastal floods resulted in huge loss of lives and property even greater than extreme events like TCs landfall (Moftakhari et al. 2017). In this context, this study has motivated to address the inadequacy of the TC occurrence dataset of upper atmospheric zones in the BoB coastal region over the last 40 years. In addition to this, glacier and ice melting due to the increased temperature resulting from the mean sea level rising they were also restarting the occurrences of TCs events that claim enormous economic and social losses which were being unnoticed (Bamber et al. 2018; Cazenave et al. 2019; Spada 2017; Chen et al. 2017). It is proven that if the possible landfall of TCs can be identified at an earlier time, probable damage control would be possible (Paliwal and Patwardhan, 2013; Weinkle et al., 2012; Singh et al., 2012).

Synoptic climatology has been proven a potential field of research to identify regional and global climate patterns around the globe using statistical analysis (Barry and Carleton, 2001; Wahiduzzaman et al., 2020b; Wahiduzzaman et al., 2021a). Statistical analysis of weather variables associated with TCs activity can help policymakers, land planners, and coastal residents take proper action in advance. To linkage the statistical relationship between TCs and weather parameters, it is crucial to know the influential factors such as weather regimes, geopotential height, sea level pressure, wind flows, etc. that affect TCs genesis and landfall (Reinhold and Pierrehumbert, 1982; Michelangeli et al., 1995; Rudeva et al., 2019). A few cited works have explored the impact of upper atmospheric and oceanic conditions on the variation of TCs event in the BoB (Sengupta et al., 2007; Girishkumar and Ravichandran, 2012; Felton et al. 2013; Wahiduzzaman et al. 2017; Sattar and Cheung 2019). Gaona et al. (2018) and Zhou et al. (2018) studied TCs activity over the BoB, resulting in disastrous impact by heavy floods and winds with the association of enormous rainfall and surges. However, these earlier works have hardly examined the statistical association between synoptic climatology and TCs events over the BoB and the surrounding coastal region.

Multivariate statistical approaches like Principal Component Analysis (PCA) and clustering have been a potential tool that used in many fields ((i.e. Blasius and Greenacre, 2014; Bro and Smilde, 2014; Hair et al. 2006; Hou et al. 2015; Kline, 2014; Shlens, 2014; Duke et al. 1985). PCA has also been used by many scientists, i.e. Farukh and Yamada (2014), Farukh et al. (2014) and Islam et al. (2021), to identify severe snowfall, flood, tropical cyclone phenomena and its synoptic climatology. PCA has been proven effective in studying vulnerability assessment, health vulnerability and disaster risk reduction (Miller, 2014; Howe et al., 2013; Zhu et al. (2014); Fisher et al. (2015); Tasnuva et al., 2020; Siddique et al., 2021). On the other hand, the general circulation model (GCM) has been used to determine the effect of climate extremes on 
agriculture (Glibert et al., 2014; lyalomhe et al., 2015; Rahman et al. 2017; Farukh et al. 2014; Das 2021), rising of sea level and coastal surges (Neumann et al. 2015) and so on. Ruane et al. (2013) found that increased emissions also affected coastal agriculture coupled with the changing climate. Some GCM models have been used to predict storm surge and atmospheric circulation patterns (Maw et al., 2017). Many scientists were successfully adopted GCM models in simulating the level of inundation but remain poorly understand the coastline structures with the definite progressions of wave circulation, breaking, and interface (Sielecki and Wurtele, 1970; Flather and Heaps, 1975). On the other hand, Ghosh et al. (1983), Flather and Khandaker (1987), Katsura et al. (1992) were able to develop some numeral models to simulate storm surges of BoB. Additionally, Esteban et al. (2005) applied both PCA and clustering in daily sea-level pressure rotations and found that snowfall was less than $30 \mathrm{~cm}$ per day patterns. However, due to a lack of direct observations and instruments, upper atmospheric conditions of climatic parameters triggering TCs events and possible future changes in their frequency and intensity caused by climate change is poorly understood in the BoB.

This work fills to close this knowledge gap in the existing literature. The study's primary objective is to examine synoptic climatology of weather parameters associated with extreme TCs events in the BoB and to explore the reasons behind severe TCs formation in the nearby coastal region. This study adopted PCA and clustering methods to identify the most responsible variables (i.e. Sea level pressure, temperature) that play a pivotal role in forming severe TCs events. The GCM model was also used to visualize the instability of those weather variables (sea level pressure and temperature) in the total atmospheric column on the TCs occurring days.

\section{Data And Methods}

\subsection{Study region description}

The southern coastal region of Bangladesh, which lies within 21 23" $\mathrm{N}$ and 89 93"E were chosen as the study areas where the occurrence of monsoon cyclones is frequent that affect the current agriculturally based economy (WARPO, 2006) (Fig. 1). The average temperature of these areas ranges from $18^{\circ} \mathrm{C}$ to 28 ${ }^{0} \mathrm{C}$ where the average maximum has found in May, and the minimum was seen in January (Rahman and Ferdousi, 2011; Das and Islam 2021).

From 1975 to 2014, lots of TCs hit on Bangladesh. For example, some of the disastrous cyclones were reported in 1985, 1988, 1991, 1994, 1995, 1997, 1998, 1999, 2000, 2001, 2002, 2003, 2004, 2007, 2009 and 2013 (Table S1) Among these, cyclone SIDR in 2007 and cyclone AILA in 2009 was most destructive in terms of damage of properties and fatalities (BBS, 2014). Most importantly, all the cyclones stroke in the southern part as the area is a coastal area of Bangladesh (Table S2). That is why this area has been selected for the synoptic study of cyclone events in the past 40 years. Datasets were collected from Satkhira, Khulna, Mongla, Khepupara, Barishal, Bhola, Patuakhali, Hatiya, Chandpur, Feni's meteorological station Sandwip, Sitakunda, Chittagong, Kutubdia, Cox's Bazar and Teknaf (Fig. 1). 


\subsection{Data sources and quality check}

We collected data on 22 TCs that hit the coastal region from 1975-2014 and caused severe destructions. Weather variables, i.e. sea level pressure (SLP) and Temperature data, were collected from the BMD of the study areas. Three hourly data of every parameter were collected and then compiled, tabulated into daily data to avoid any deviance and then analyzed according to the study's objectives.

Historical records of TCs that attacked Bangladesh were collected from the Disaster Preparedness Center, Asian Institute of Technology (AIT) and Bangladesh Bureau of Statistics (BBS). These data were then plotted following the arrangement of day/month/year. We collected air pressure data between $120 \mathrm{~N} \neg$ to $320 \mathrm{~N}$ latitude and 780E to 1020E longitudes from NCEP (National Centers for Environmental Prediction) Reanalysis of NOAA (National Oceanic and Atmospheric Administration) / ESRL (Earth System Research Laboratory), Physical Science Division, USA (United States of America). NCEP (National Centers for Environmental Prediction) global Circulation modelling was applied to develop a map and analyze air pressure. We also concentrated on the possible association of TCs events with the synoptic climatology of SLP and air temperature. The BMD staff was initially the checked quality control of the dataset. A twosample Student's t-test was performed to assess the dataset's statistical significance where the outcomes are significant at a $95 \%$ confidence level for all TCs occurrence days.

\subsection{Principal Component Analysis (PCA)}

We used PCA to understand the core affiliation among the allied variables through a small set of factors. PCA is used to convert variables that are correlated in any way into uncorrelated observations that are linear calling principal components. Lastly, PCA produced a set of variables of vectors that were not associated in orthogonal basis (Zhu et al., 2014; Jolliffe, 2002). Yarnal (1993) used S mode (grid points as variables and days as observations) centred data matrix PCA, which used the standardized spatial SLP data, which also maintained the original characteristics such as original daily temporal scale (Esteban et al., 2005). Barry and Carleton (2001) showed that the correlation matrix provides the best proficient demonstration. Lastly, we used the varimax procedure, which assists the spatial analysis of principal components used by Yarnal (1993). We used the scree test to define the factors which describe the special ratio of the total variance by Cattel, 1966. The KMO values range from 0 to 1 , where the value between 0.8 and 1 indicates that the number of samples is adequate, where the value less than 0.6 means that the sampling is not sufficient, and possible remedial measures should be taken. The scree test results showed in our study that it was acceptable according to the range of the KMO values.

\subsection{K-mean clustering method}

We used the nonhierarchical K-means method to clustering the remarks (Hair et al., 1998). Cluster analysis is used to grouping a set of data that have the very homogeneous characteristics of algorithms. Many scientists have used clustering in their study to separate homogenous data into a group (Anderberg, 2014; Duran \& Odell, 2013; Tan et al., 2013). In this study, we also used this wide-ranging method to identify the groups of cyclones with similar characteristics, i.e. temperature and SLP. The 
number of groups and centroids were decided according to the PCA results, which establish the spatial variation patterns. Centroids and groups were created using the Birkeland et al. (2001) and Tait and Fitzharris (1998) method. Using K-means was to classify the distribution of Temperature and SLP values with a similar characteristic. For Temperature and SLP, atmospheric circulation clusters were formed by using the synoptic map.

\subsection{General Circulation Model (GCM)}

The GCM is the most complicated climatic model developed by Viner (2000), which displays the threedimensional climatic scenario of the components used to represent the components. We followed the method applied by Onogi et al. (2007), the data of deadly 22 TCs landfalling periods, i.e. with synoptic weather parameters like SLP and temperature were obtained from Japanese 25-year reanalysis project (JRA-25) by the Japan Meteorological Agency (JMA) with a $1.125^{\circ}$ spatial resolution encircling by $12^{\circ} \mathrm{N}-$ $32^{\circ} \mathrm{N}$ and $78^{\circ} \mathrm{E}-102^{\circ} \mathrm{E}$. A detailed description of the GCM model can be found in Onogi et al. (2007).

\section{Results}

\subsection{Clustering analysis}

Figure 2 represents the clustering of 22 cyclones from 1975-2014. From figure 2, it is clearly understood that the most important factors, i.e. SLP and Temperature responsible for the formation of $22 \mathrm{TCs}$, have been grouped into 3 clusters (centroid). The cyclonic factors which characteristics are similar are in the same cluster as we can see from the figure that circle with green colour is considered cluster 1 where the temperature was $41.70 \mathrm{C}$, and sea level pressure was $995.7 \mathrm{hPa}$.

So, cluster 1 indicates that $41.70 \mathrm{C}$ temperature was responsible for one cyclone out of 22 TCs from 19752014. In cluster 2, 9 circles with red colour have presented, which have considered the same characteristics for occurring nine cyclones in 40 years we studied. The temperature triggered behind the formation of $9 \mathrm{TCs}$ was from $300 \mathrm{C}$ to $36.2 \mathrm{OC}$ where the sea level pressure was from $991.8 \mathrm{hPa}$ to 999.7 $\mathrm{hPa}$. The centroid two is pointing at $33.50 \mathrm{C}$, which is the average of these nine red circles. So, these results indicate that temperature above $300 \mathrm{C}$ was mostly responsible for low atmospheric pressure, which turns into cyclonic activity. The rest of the 12 black circles have been considered under the third centroid, where the circles are in the same characteristics for the formation of the rest of 12 TCs from 1975-2014. The SLP behind these TCs formation was below $990 \mathrm{hPa}$, and temperature also ranged from $300 \mathrm{C}$ to $390 \mathrm{C}$.

\subsection{Sea level pressure anomaly and severe TCs}

This section described the scenario of the different atmospheric pressure levels and temperatures of the 22 TCs occurring days.

\subsubsection{Cluster 1}


Figures 3 represented the composite geographical distribution of SLP anomalies compared with the climatology from 1975 to 2014 of cluster 1 for surface level, $850 \mathrm{hPa}, 700 \mathrm{hPa}, 500 \mathrm{hPa}$ and $300 \mathrm{hPa}$. Figure 3 illustrates SLP ( $\mathrm{hPa}$ ) from $120 \mathrm{~N}$ to $320 \mathrm{~N}$ latitude and 780E to $1020 \mathrm{E}$ longitude derived from NCEP, NOAA/ESRL Physical Science Division. In the clustering part, we have seen that only one cyclone has passed in the last 40 years have followed different characteristics among 22 TCs.

It is indicated that a tough negative anomaly was present over the BB and the southern part of Bangladesh (Fig. 3a). Deep depression of SLP was observed over the south-eastern and southern coastal regions. A slightly lighter depression was observed throughout the whole of Bangladesh except the easternmost part of the country.

At $850 \mathrm{hPa}$, a dice-shaped strong negative anomaly of SLP was observed over Myanmar. A slightly lower depression was observed near the eastern and southwestern parts of the country. A lighter depression was observed throughout the whole country (Fig. 3b).

Complete desertion of adverse abnormality was observed at above $700 \mathrm{hPa}$ level (Fig. 3c). This positive anomaly was expanded all over Bangladesh and over BB. Deep negative depression of SLP was observed in the southwestern part of Myanmar that also can cause a very unstable condition in the upper atmosphere. At 500hPa height, a strong negative anomaly was observed over India in the north-eastern part of Bangladesh (Fig. 3d). This oval-shaped deep depression was as large as Bangladesh.

A relatively low depression could observe all over Bangladesh in those cyclones occurring days. In figure $3 e$, it is seen that at $300 \mathrm{hPa}$ height, a deep depression was observed in the Northern part of Bangladesh over India. The atmosphere over Bangladesh was very clear, and a positive anomaly was observed. This positive anomaly at this higher atmosphere could create a very unstable weather condition at this height of the atmosphere.

A comparison of amalgamated geographical dispersal of synoptic temperature from the specified level has shown in Fig. 4. Fig. 4a showed the surface air temperature anomaly, which is undoubtedly displayed from the Figure. There's a progressive external air temperature irregularity region above the eastern and southeastern part of Bangladesh. This positive anomaly is prominent over the whole coastal part of Bangladesh, which is noticeable over West Bengal of Indian territory. This positive anomaly zone was also available on the eastern border of Bangladesh, covering India and some parts of Myanmar also. A negative anomaly zone has been indicated in the southern-eastern part of Myanmar and the northernwestern part of Thailand and Laos. From the results, we can say that outward level air temperature in Bangladesh and India was somewhat warmer than in Myanmar, Thailand and Laos, where the air is much cooler on this cyclone occurring day.

Figure $4 \mathrm{~b}$ showed a tough, positive air temperature irregularity region at $850 \mathrm{hPa}$ level over southwestern Bangladesh. The strong positive zone anomaly covers the part of Bangladesh from $24.50 \mathrm{~N}$ to the south of its area. The alteration region between warmer and cooler anomalies was occurred over the central 
part of Myanmar, keeping one strong positive zone over southeastern India and the central-western portion of Myanmar.

But at around $3,000 \mathrm{~m}$ above $(\sim 700 \mathrm{hPa})$ from outward, there was the complete vanishing of warmer zones (Fig. 4c). The appearance of some part of the negative zone was found in the southeastern part of Bangladesh and in from central to the southern part of Myanmar. Thus, this cooler zone at a relatively upper atmosphere would not affect creating an unstable atmosphere.

The temperature distribution map showed that the temperature anomaly at the most influential weather zone of the upper atmosphere was at $500 \mathrm{hPa}$ level (Fig. 4d). A strong negative area at $500 \mathrm{hPa}$ level surrounded the southwestern part of Bangladesh, and BB was noticed. This situation implies the formation of a cooler region at around $6,000 \mathrm{~m}(\sim 500 \mathrm{hPa})$ over the surface. At $300 \mathrm{hPa}$ level $(\sim 10,000 \mathrm{~m}$ above), occurrences were observed where a wide-ranging area was covered by warmer air from Tibet to $\mathrm{NIO}$ and the eastern part of India (Fig. 4e), where the regions of Bangladesh were subjugated by a deep warmer area which can be resulted in a severe instability throughout the whole atmospheric column.

\subsubsection{Cluster 2}

In the clustering part, we have seen that nine TCs passed in the last 40 years following the same characteristics among the 22 TCs. These conditions, which have played a big role in forming those cyclones, have fallen under cluster 2 .

The climatological comparison of combined geographical dispersal of SLP variances from 1975 to 2014 of cluster 2 for surface level, $850 \mathrm{hPa}, 700 \mathrm{hPa}, 500 \mathrm{hPa}$ and $300 \mathrm{hPa}$ can be seen in Figure 5(a), 5(b), 5(c), $5(d)$ and 5(e).

From Fig. 5a, it can be seen that a strong negative depression of SLP was prominent in the southerly region of Bangladesh and above the BB. This oval-shaped depression was as large as the size of Bangladesh. In contrast, the remaining BoB portion has a relatively low depression of SLP, except for the north-eastern and north-western parts of the country.

Figure $5(\mathrm{~b})$ shows that at $850 \mathrm{hPa}$, a strong negative anomaly existed over the $\mathrm{BoB}$, and it was prominent toward the Bangladesh coastal and hilly region. The rest of the parts had a normal SLP at this height. These two states of weather conditions at this height can cause a very unstable condition resulting in very extreme cyclonic events.

At $700 \mathrm{hPa}$, about $3000 \mathrm{~m}$ above, we can observe a relatively large shaped negative depression of SLP above BB and the south-easterly region of Bangladesh, which was larger than Bangladesh in diameter. In the rest of the country's area, the weather condition was very normal (Fig. 5c). These two different conditions can result in a very unstable weather event. At $500 \mathrm{hPa}$, from Fig. $4 \mathrm{~d}$, a very strong negative anomaly was observed over BoB and the south-eastern part of Bangladesh and India. 
At the $300 \mathrm{hPa}(\sim 10,000 \mathrm{~m}$ above) height from the surface (Fig. 5e) there a complete disappearance of negative anomaly zones was observed. These two different zones of negative and positive anomaly can result in a serious weather-related extreme event.

Evaluation of combined geographical dispersal of synoptic temperature from the specified level can be seen in Fig. 6. The warmer outer air temperature irregularity region is prominent above the easterly and south-easterly portions of Bangladesh. The day the cyclone hit; a cooler zone was expanding from the Indian terrain towards the south-westerly landscape of Bangladesh. At the same time, a strong cooler zone is also seen in the southern coastal region of Bangladesh.

These two coexistences of the negative zone over the Indian Territory and the southern part of Myanmar possessed the moving area over the south part of Bangladesh to the BoB. The results suggest domination of comparatively colder temperatures in the southerly region not much above the exterior level, especially on cyclone incidence. The area was mostly cooler in the southern-western part than the southern-central and southern-eastern region of Bangladesh on the cyclone befalling days at surface level.

An irregular warmer air temperature area above the north-easterly region of Bangladesh was seen at 850 $\mathrm{hPa}$ level. Two negative and positive anomaly zones above south-eastern India and southern Myanmar and BoB created a transitional site (Fig. 6b). But nearly 3000m (700hPa) above the sea level (Fig. 6c). This warmer area surrounded the northeast, south-east and above BB. An unstable atmospheric situation might have resulted through this unstable situation which could interact with the surface.

A tough warmer area surrounding the south-westerly region of Bangladesh and above the surface level of BoB pointed to a progression of positive part nearly over $6000 \mathrm{~m}(5000 \mathrm{hPa})(\mathrm{Fig} .6 \mathrm{~d})$. An intense occurrence at $300 \mathrm{hPa}(\sim 10,000 \mathrm{~m}$ above) level was seen by Fig. 6e, where an expanded area was concealed by progressive irregularity encompassing Tibet to North Indian Ocean (NIO) via eastern Indian Territory. Bangladesh was subjugated by an advanced irregularity zone forming a profound warmer area above these zones. A large unstable zone can result through the atmospheric column.

\subsubsection{Cluster 3}

The conditions that have played a pivotal role in forming the rest 12 TCs have fallen under cluster 3 . Fig. 7 represents the merged geographical dispersal of SLP irregularities paralleled with the climatology from 1975 to 2014 of cluster 3 for surface level, $850 \mathrm{hPa}$ and $700 \mathrm{hPa}, 500 \mathrm{hPa}$ and $300 \mathrm{hPa}$. From Fig. $7 \mathrm{a}$, it is clear that a strong negative anomaly existed over BoB. This negative anomaly was prominent in Bangladesh.

From Fig. $7 \mathrm{~b}$, at $850 \mathrm{hPa}$ from the surface, the same situation was observed over the BoB, and it was also prominent towards Bangladesh. The same situation was observed at the height of $700 \mathrm{hPa}$, from Fig. 7c, but the negative anomaly was relatively bigger than the other level. This strong negative anomaly over BB also covers the southern lower part of the Bangladesh coastal region. But a slightly lighter negative 
anomaly was observed throughout Bangladesh. But noticeably, a huge area from Myanmar to India was covered by a positive anomaly.

At the $500 \mathrm{hPa}$ height, deep depression of SLP is observed over BoB and India. This circular shape deep depression also covered the southern part of the coastal region and a small part of the south-eastern part of Bangladesh. The perimeter of this depression is almost equal to the size of Bangladesh. In these cyclonic days, a slightly lower depression was observed over BB and India, prominent towards the NIO.

The most dramatic situation was observed at $300 \mathrm{hPa}$ height in these cyclones occurring days (Fig. $7 \mathrm{~b}$ ). A positive anomaly throughout Bangladesh is observed. Though, a slightly negative anomaly was observed over BB. A deep negative anomaly was observed over NIO and south-eastern India. The positive anomaly at this height and negative anomaly below this height could result in serious instability throughout the whole atmosphere.

A comparison of the composite geographical distribution of synoptic temperature from the specified level has shown in Fig. 8. Fig. 8a shows the surface-level air temperature anomaly. It was clearly shown that the positive surface air temperature anomaly region was almost disappeared from the map except for some small areas of $\mathrm{NIO}$ though they are not strong enough. The day when cyclones befall, the robust adverse irregularity region from Indian Territory extended toward all over Bangladesh and expanded to the whole of south-east Asia. A transition zone over the Bay of Bengal to the NIO Territory was observed since the positive zone and negative zone coexists over the Indian Territory and the whole part of Myanmar. On the day of occurrence, relatively cooler air temperature dominance was observed in the southerly region, especially near the surface. The area is mostly cooler on the southern-western and central-western part than the southern-central and southern-eastern part of Bangladesh on the cyclone occurring at surface level.

Fig. $8 \mathrm{~b}$ represented a serious negative air temperature irregularity region over the southern-western area of Bangladesh at $850 \mathrm{hPa}$ level. A transitional zone above BB with a double negative region above southwesterly India and southerly Myanmar was observed. Around $3000 \mathrm{~m}(700 \mathrm{hPa})$, a disappearance of this zone was noticed over Bangladesh. A warmer zone existed from the northeast to the southern parts of Bangladesh, and it extended up to BoB. This warmer region in a comparatively upper atmosphere might result in an unbalanced atmosphere over the thermal uncertainty relating to surface level.

$500 \mathrm{hPa}$ level is considered the most influential upper atmospheric weather zone (Fig. 8d). A positive anomaly zone circling above the south-westerly region of Bangladesh and above BB dictates the progress of the warmer region at the height of $6000 \mathrm{~m}$ near the surface. At $300 \mathrm{hPa}$ level $(\sim 10,000 \mathrm{~m}$ above), a larger area covering by positive irregularity region expanded from Tibet to NIO via eastern Indian territory caused the major instanced occurrence (Fig. 8e). The total area of Bangladesh was subjugated by a positive irregularity zone, which indicates a huge warmer region over these areas. The development of a larger unstable zone through the whole atmosphere could result from this bigger warm air mass. 


\section{Discussion}

In this paper, we define the extreme TCs events as those events that were the most destructive and claimed the loss of hundreds of lives and millions of properties. The climate of the North Indian Ocean region is highly affected by oceanic variability on different spatiotemporal levels (Schott and McCreary 2001). Many scientists studied these extreme events because of their paucity and nature of occurrence (Ali, 1999; Webster, 2008; Mohapatra et al., 2014; Wahiduzzaman et al., 2017; Wahiduzzaman et al., 2020a, Islam et al., 2020; Wahiduzzaman et al., 2021a). This study intends to examine the association of the atmospheric condition responsible for the TCs occurring days for 22 deadliest TCs from 1975-2014. It was found that among the 22 TCs, we studied 12 TCs happened under the same atmospheric situation when the SLP was below $990 \mathrm{hPa}$, and the temperature ranged from $30.90 \mathrm{C}$ to $390 \mathrm{C}$. On these cyclone ensuing days, a serious negative anomaly of SLP was observed at surface level, 850hPa, 700hpa and $500 \mathrm{hPa}$ level whereas, a complete absence of negative depression was observed at $300 \mathrm{hPa} \mathrm{GPH}$ over the $\mathrm{BoB}$ and southern part of the country.

On the other hand, a positive temperature was observed in the surface level and $850 \mathrm{hPa}$ and $700 \mathrm{hpa}$ levels. On the contrary, the complete disappearance of the positive anomaly zone was prominent at $500 \mathrm{hPa}$. Again, a positive anomaly zone at the $300 \mathrm{hPa}$ was the most dramatic situation at this $\mathrm{GPH}$, resulting in the severe instability of the atmospheric zone, causing deadly cyclones. Farukh and Yamada (2014) were found a negative anomaly that triggered the extreme snowfall event at $300 \mathrm{hPa} \mathrm{GPH}$. Moreover, it also found that the consequence of SLP negative anomaly occurred in the equatorial eastern pacific El-Nino and Central pacific El-Nino (Sun et al., 2013; Maw and Jinzhong 2017; Wahiduzzaman et al., 2021b). A recent study was done by Gaona et al. (2018), and Zhou et al. (2018) using synoptic climatology showed that tremendous rainfall and surges occurred, which was the consequence of heavy floods and winds that caused by extreme TCs place over the BoB, resulting in huge damages to the society and economy. This also supports that synoptic study of extreme events is essential for advancing the field of planning, forecasting and management.

Nine TCs were formed where the SLP was below $1000 \mathrm{hPa}$, and the temperature ranged from $300 \mathrm{C}$ to 36.20C. On these TCs occurring days, a strong negative anomaly of SLP was observed at surface level, $850 \mathrm{hPa}$ and $700 \mathrm{hPa}$ level over BB. The depression turned larger at $500 \mathrm{hPa}$ level height, but dramatically this depression was completely disappeared at $300 \mathrm{hPa} \mathrm{GPH}$ over the $\mathrm{BoB}$ and the entire coastal region of Bangladesh. On the other hand, a cooler air temperature was observed at the surface level, where a complete departure was followed at $850 \mathrm{hPa}$ and $700 \mathrm{hPa}$ levels. This co-existence of positive and negative temperature zones in the immediate atmospheric level could be triggering the most destructive atmospheric instability at these levels. This kind of phenomenon was observed for causing many unusual atmospheric phenomena in many parts of the world, i.e. negative anomalies at the $700 \mathrm{hPa}$ height over the eastern North Pacific Ocean and the western USA also affect above-average snowfall accumulation (McCabe and Legates, 1995). During the pre-monsoon season, an elevated thermal unstable region and a vertical wind shear in the higher atmospheric zone was observed by Yamane and Hayashi (2006). Our research also indicates that negative anomaly in different atmospheric levels 
triggers deadly TCs events over the BoB. A study done by Farukh et al. (2019) showed that a higher temperature at $850 \mathrm{hPa}$ to $300 \mathrm{hPa}$ levels could be followed by extreme weather phenomena like TCs when agricultural production was seriously damaged. Several scientists also reported a similar result (e.g., Glibert et al. 2014 and lyalomhe et al. 2015; Islam et al., 2020). Ruane et al. (2013) showed that coastal agriculture is being affected by higher emissions of pollutants under the climate change scenario.

Of these 22 TCs, only one event was formed when the atmospheric circumstance was completely different, and the SLP was above $1000 \mathrm{hPa}$, and the temperature was $41.70 \mathrm{C}$. In this TCs occurring day, the total coastal area was subjugated by a negative anomaly zone up to $300 \mathrm{hPa}$ level indicates the development of a huge depression region over this zone. Many researchers have also found that the larger depression area at the upper atmosphere develops bi vertical wind shear perpendicular wind shear through the total atmospheric column, resulting in severe weather events. Yamane et al. (2012) also have noticed a trough at $550 \mathrm{hPa}$ on severe local convective storm days.

Synoptic climatology is an emerging field in scientific research for planning, forecasting, managing disaster damages, and reducing disaster risk. Scientists have identified that tremendous economic and social losses were being unnoticed caused by extreme cyclone events boosting sea level rising due to the upward of temperature (Spada 2017; Chen et al. 2017; Bamber et al. 2018; Cazenave et al. 2019). If the possible landfall of TCs can be forecasted earlier, the damage control also would be significant (Paliwal and Patwardhan, 2013; Weinkle et al., 2012; Singh et al., 2012; Maw et al., 2017). However, the limitation of the study cannot be overlooked. Although unbiased correction was performed in this work, some missing datasets were found from the BMD. We removed the missing datasets before tabulating the TCs event. There was the unavailability of recent weather variables and TCs datasets. The more updated current datasets can be used in this research to obtain better results. These deserve further examination.

\section{Conclusion}

This paper explores the association between the weather parameters and TCs events and discusses TC genesis using multivariate statistics and the GCMs model. In this study, we found that the atmospheric instability in different atmospheric zones of the upper ambience triggered many disastrous TCs in the coastal regions and the whole country in the last four decades. From the outcomes of the GCMs model, it is observed that TC events and SLP might be very promising variables for disaster scientists to aid the early forecasting of deadly TCs. We identified a large depression of SLP and erratic temperature anomalies at the upper atmosphere that can cause an unstable atmospheric level that leads to extreme TCs events. To understand the upper atmospheric situation in TC occurring days, this research's outcomes will help establish a policy and preparedness plan for TC prediction. For planning and disaster management, forecast, intensification, and the movement of the TCs, this study will be helpful to measure the vulnerability due to climate change with a special emphasis on extreme TCs. Composite mapping of climate change indices using GCM technology is a strong tool to analyze extreme weather events, especially TCs. Determination of synoptic climatology is very useful for policymaking, planning, disaster mitigation, and saving local inhabitants and the agricultural sector from cyclone hazards. So, the 
present work will assist the understanding the synoptic climatology associated with SLP and temperature to identify the reasons behind extreme TCs formation in the BoB.

\section{Declarations}

\section{Acknowledgement}

The authors would like to express their gratefulness to the Bangladesh Meteorological Department (BMD) and the NOAA for sharing dataset for this research.

\section{Ethical approval}

Not applicable

\section{Consent to Participate}

Not applicable

\section{Consent to Publish}

Not applicable

\section{Data availability}

Data are available upon request on the corresponding author

\section{Code availability}

Not applicable

\section{Author contributions}

M.A.B and M.A.M.H, designed, planned, conceptualized, drafted the original manuscript, and M.A.B, and M.A.M.H were involved in statistical analysis, interpretation; M.A.B and M.A.K., contributed instrumental setup, data analysis, validation; A.R.M.T., M.A. B and M.A.M.H., contributed to editing the manuscript, literature review, proofreading; M.A.K. M.A.B and A.R.M. T.I., were involved in software, mapping, and proofreading during the manuscript drafting stage.

\section{Conflict of interest}

There is no conflict of interest to publish this work.

\section{Funding statement}

None 


\section{References}

1. Abrol V (1987). Application of a Linear Surge Model for the Evaluation of Storm Surges along the Coastal Waters of Kalpakkam, East Coast of India. Ind. J. M. Sci. 16: 1- 4

2. Adger WN (2006). Vulnerability. Global Environmental Change, 16(3), 268-281. Ahmed N, OcchipintiAmbrogi A, Muir JF (2013). The impact of climate change on prawn postlarvae fishing in coastal Bangladesh: Socioeconomic and ecological perspectives. Marine Policy, 39, 224-233

3. Alam MdM, Hossain MdA, Shafee S (2003) Frequency of Bay of Bengal cyclonic storms and depressions crossing different coastal zones. Int J Climatol 23:1119-1125

4. Balaguru K, Taraphdar S, Leung LR, Foltz GR (2014) Increase in the intensity of postmonsoon Bay of Bengal tropical cyclones. Geophy Res Let 41:3594-3601

5. Bamber JL, Westaway RM, Marzeion B, Wouters B. (2018) The land ice contribution to sea level during the satellite era. Environ Res Lett 13(6): Art. No. 063008. https://doi.org/10.1088/17489326/aac2fo.

6. Barry RG, Carleton AM (2001). Synoptic and Dynamic Climatology. Routledge. 620p.

7. BBS (Bangladesh Bureau of Statistics) (2014) Bangladesh Bureau of Statistics, Statistics Division, Ministry of Planning, Statistical Year Book of Bangladesh - 2010. BBS, Dhaka, Bangladesh

8. Birkeland KW, Mock CJ (1996) Atmospheric circulation patterns associated with heavy snowfall events, Bridger Bowl, Montana, USA. Mount Res Devmnt 16:281-286

9. Birkeland KW, Mock CJ, Shinker JJ (2001) Avalanche extremes and atmospheric circulation patterns. Ann Glaciolog. DOl:http://dx.doi.org/10.3189/172756401781819030

10. Blasius J, Greenacre M (eds) (2014) Visualization and verbalization of data. CRC Press

11. Bro R, Smilde AK (2014) Principal component analysis. Anal Methods 6(9):2812-2831

12. Cattell RB (1966) The Scree test for the number of factors. Mult Vib Behavrol Res 1:245-276

13. Cazenave A, Hamlington B, Horwath $M$ et al (2019) Observational requirements for long-term monitoring of the global mean sea level and its components over the altimetry era. Front Mar Sci 6(582):2296-7745

14. Chen XY, Zhang XB, Church JA, Watson CS, King MA, Monselesan D, Legresy B, Harig C (2017) The increasing rate of global mean sea-level rise during 1993-2014. Nat Clim Change 7(7):492-495

15. Coleman JSM (2005). Atmospheric circulation types associated with cause-specific mortality in the central United States. Ph.D. dissertation, The Ohio State University, 264p.

16. Das PK (1972). A prediction model for storm surges in the Bay of Bengal. Nature. 239: 211-213

17. Das S, Islam ARMT (2021) Assessment of mapping of annual average rainfall in a tropical country like Bangladesh: remotely sensed output vs. kriging estimate, Theoretical and Applied climatology, DOI: 10.1007/s00704-021-03729-3

18. Das S (2021) Extreme rainfall estimation at ungauged locations: Information that needs to be included in low-lying monsoon climate regions like Bangladesh. J Hydrol 601:126616 
19. Dube SK; Sinha PC and Roy GD (1985). The numerical simulation of storm surges along the Bangladesh coast. Dynam Atm Oceans 9: 121-133

20. Duran BS, Odell PL (2013) Cluster analysis: A survey, vol 100. Springer Science \& Business Media

21. Esteban P, Jones P, Martin J, Mases M (2005) Atmospheric circulation patterns related to heavy snowfall days in Andorra, Pyrenees. Int J Climatol 25:319-329

22. Farukh MA, Yamada JT (2014). Synoptic climatology associated with extreme snowfall events in Sapporo city of northern Japan. Atm. Sci. Lett. DOI:

23. Felton CS, Subrahmanyam B, Murty VSN (2013) ENSO-modulated cyclogenesis over the Bay of Bengal. J Clim 26:9806-9818

24. Fisher B, Ellis AM, Adams DK, Fox HE, Selig ER (2015) Health, wealth, and education: The socioeconomic backdrop for marine conservation in the developing world. Mar Ecol Prog Ser 530:233-242

25. Flather RA, Heaps NS (1975). Tidal computations for Morecambe Bay. Geophysics. J. R. Astr. Soc. 42: $489-517$

26. Flather RA, Khandker $\mathrm{H}$ (1987). The storm surge problem and possible effects of sea level changes on coastal flooding in the Bay of Bengal. Int. Workshop on Climatic Change, Sea Level, Severe Tropical Storms and Associated Impacts, UNEP. Norwich, England

27. Gaona MFR, Overeem A, Raupach TH, Leijnse H, Uijlenhoet R (2018) Rainfall retrieval with commercial microwave links in São Paulo. Brazil Atmos Meas Tech 11:4465-4476. https://doi.org/10.5194/amt-11-4465-2018

28. Ghosh SK, Dewan BN, Singh BV (1983). Numerical simulation of storm surge envelops associated with the recent severe cyclones impinging on the east and west coast of India. Mausam., 34: 399404.

29. Girishkumar MS, Ravichandran M (2012) The influences of ENSO on tropical cyclone activity in the Bay of Bengal during October-December. J Geophys Res Ocean, 117, doi:10.1029/2011JC007417

30. Glibert, P. M., Icarus Allen, J., Artioli, Y., Beusen, A., Bouwman, L., Harle, J.,... Holt, J. (2014). Vulnerability of coastal ecosystems to changes in harmful algal bloom distribution in response to climate change: Projections based on model analysis.Global Change Biology, 20(12), 3845-3858

31. Hair JF, Black WC, Babin BJ, Anderson RE, Tatham, R. L. (2006). Multivariate

32. Hair JF, Anderson RE, Tatham RL, Black WC (1998). Multivariate Data Analysis, 5th ed. Prentice-Hall International: New Jersey, NJ

33. Hebenstreit GT, Gonzalez FI, Morris AF (1985). Near-shore tsunami simulation of Valparaiso Harbor, Chile. Proc. Int. Tsunami Symp.

34. Hibberd S and Peregrine DH, (1979). Surf and run-up on a beach: a uniform bore. J Fluid Mech 95: 323- 345

35. Hou K, Li X, Zhang J (2015) GIS analysis of changes in ecological vulnerability using a SPCA model in the loess plateau of Northern Shaanxi, China. International Journal of Environmental Research 
Public Health 12(4):4292-4305

36. Howe C, Suich H, van Gardingen P, Rahman A, Mace GM (2013) Elucidating the pathways between climate change, ecosystem services and poverty alleviation. Current Opinion in Environmental Sustainability 5(1):102-107

37. Islam ARMT, Nafiuzzaman M, Rifat J, Rahman MA, Chu R, Li M (2020) Spatiotemporal variations of thunderstorm frequency and its prediction over Bangladesh, Meteorology and Atmospheric Physics, 132 (6): 793-808, Doi: 10.1007/s00703-019-00720-6

38. Islam ARMT, Talukdar S, Mahato S, Kundu S, Eibek KU, Pham QB, Kuruki A, Linh NTT (2021) Flood susceptibility modelling using advanced ensemble machine learning models. Geosci Front $12: 101075$

39. Iyalomhe F, Rizzi J, Pasini S, Torresan S, Critto A, Marcomini A (2015) Regional Risk Assessment for climate change impacts on coastal aquifers. The Science of the Total Environment 537:100-114

40. Jackson, A. L. (1985). Estimates of climatic air quality potential at Shreveport, Louisiana. J. Climate Appl. Meteor. 24: 293-301.

41. Jolliffe IT (1986) Principal Component Analysis. Springer-Verlag, New York

42. Jones B, Ali A (1980) The numerical modeling of storm surges in the Bay of Bengal. Q J Rol Meteorol Soc 106:1-18

43. Kalkstein, L. S. (1991). A new approach to evaluate the impact of climate on human mortality. Environ. Health Perspect. 96: 145-150.

44. Kalkstein LS, Greene JS (1997). An evaluation of climate/mortality relationship in large U.S. cities and the possible impacts of a climate change. Journal of Climate Environ. Health Perspect. 105(1): 84-93

45. Kassomenos, P. A.; Flocas, H. A.; Lykoudis, S. and Skouloudis, A. (1998). Spatial and temporal characteristics of the relationship between air quality status and mesoscale circulation over an urban Mediterranean basin. Sci. Tot. Environ. 217:37-57.

46. Katusura J, Hayashi T, Nishimura H, Isobe M, Yamashita T, Kawata Y, Yasuda T, Nakagawa H (1992). Storm Surge and Severe Wind Disasters Caused by the 1991 Cyclone in Bangladesh, Research Report, No. B-2

47. Kline $P$ (2014) An easy guide to factor analysis. Routledge

48. Maw KW, Jinzhong M (2017) Impacts of Microphysics Schemes and Topography on the Prediction of the Heavy Rainfall in Western Myanmar Associated with Tropical Cyclone ROANU (2016). Advances in Meteorology, 2017, 1-22. doi:10.1155/2017/3252503

49. Maw KW, Islam ARMT, Sien ZMM et al (2017) Simulation of Storm Surge in Myanmar Coast. Earth Systems Environment 1(2):15. doi:10.1007/s41748-017-0017-7

50. McCabe GJ Jr, Legates DR (1995) Relationships between 700 hPa height anomalies and 1 April snowpack accumulations in the western USA. Int J Climatology 15:5. https://doi.org/10.1002/joc.3370150504 
51. McEntire D (1999) Issues in disaster relief: Progress, perpetual problems and prospective solutions. Dis Preven Manag 8(55):351-361

52. McGregor, G. R.; Walters, S. and Wordley, J. (1999). Daily hospital respiratory admissions and winter air mass types, Birmingham, UK. Int. J. Biometeor. 43:21-30.

53. Michelangeli PA, Vautard R, Legras B (1995). Weather regimes: Recurrence and quasi stationarity. J. Atmos. Sci. 52: 1237-1256

54. Miller SD (2014) Indicators of social vulnerability in fishing communities along the west

55. Moftakhari HR, AghaKouchak A, Sanders BF, Matthew RA (2017) Cumulative hazard: The case of nuisance flooding. Earth's Future, 5(2), 214-223. doi:10.1002/2016EF000494

56. Mohapatra M, Bandyopadhyay BK, Tyagi A, Mohanty UC (2014) Status and plans for Operational Tropical Cyclone forecasting and Warning Systems in the North Indian Ocean Region in. In:

Mohapatra M, Singh OP, Bandyopadhyay BK, Rathore LS (eds), Monitoring and Prediction of Tropical Cyclones in the Indian Ocean and Climate Change

57. Muller, R. A. (1977). A synoptic climatology for environmental baseline analysis: New Orleans. J. Appl. Meteor. 16: 20-33.

58. Neumann JE, Emanuel KA, Ravela S, Ludwig LC, Verly C (2015) Risks of coastal storm surge and the effect of sea level rise in the red river delta. Vietnam Sustainability 7(6):6553-6572

59. Paliwal M, Patwardhan A (2013) Identification of clusters in tropical cyclone tracks of North Indian Ocean. Nat Hazards 68:1-12

60. Parker CL, Lynch AH, Mooney PA (2017) Factors affecting the simulated trajectory and intensification of Tropical Cyclone Yasi (2011). Atmos Res 194:27-42

61. Qayyun MF (1983). Prediction of storm surges for Bangladesh coasts by empirical method: Results and discussions. Presented at the WMO-ESCAP Panel on Tropical Cyclones, 22-29 March, 1983, Dhaka. 12p.

62. Rahman MM, Ferdousi N (2011) Rainfall and temperature scenario for Bangladesh using $20 \mathrm{~km}$ mesh AGCM. Intr J Clim Change Strat Manag 4(1):66-80. doi:10.1108/17568691211200227

63. Rahman MA, Yunsheng L, Sultana N (2017) Analysis and prediction of rainfall trends over Bangladesh using Mann-Kendall, Spearman's rho tests and ARIMA model. Meteorol Atmos Phys 129(4):409-424. https://doi.org/10.1007/s00703-016-0479-4

64. Rajasekhar M, Kishtawal CM, Prasad MYS, Seshagiri Rao V, Rajeevan M (2014) Extended range tropical cyclone predictions for East Coast of India. In: Mohanty UC, Mohapatra M, Singh OP, Bandyopadhyay BK, Rathore LS (eds) Monitoring and prediction of tropical cyclones in the Indian Ocean and climate change. Springer, Dordrecht. https://doi.org/10.1007/978-94-007-7720-0_13

65. Reid RO and Bodine. B. R. (1968). Numerical model for storm surges in Galveston Bay. J. Wat. way. Harb. Div. 94 (WWI): 33-57

66. Reinhold, B. B. and Pierrehumbert, R. T. (1982). Dynamics of weather regimes: Quasi-stationary waves and blocking. Mon. Wea. Rev. 110:1105-1145. 
67. Ruane AC, Major DC, Winston HY, Alam M, Hussain SG, Khan AS, Rosenzweig C (2013) Multi-factor impact analysis of agricultural production in Bangladesh with climate change. Glob Environ Change 23(1):338-350

68. Rudeva I, Gulev SK, Simmonds I, Tilinina N (2014) The sensitivity of characteristics of cyclone activity to identification procedures in tracking algorithms. Tellus 66A(1):24961. doi:10.3402/tellusa.v66.24961

69. Rudeva I, Simmonds I, Crock D, Boschat G (2019) Midlatitude Fronts and Variability in the Southern Hemisphere Tropical Width. J Clim 32(23):8243-8260. doi:10.1175/JCLI-D-18-0782.1

70. Rumpf J, Weindl H, Höppe P, Rauch E, Schmidt V (2009) Tropical cyclone hazard assessment using model-based track simulation. 48(3), 383-398. doi:10.1007/s11069-008-9268-9

71. Sattar AM, Cheung KKW (2019) Comparison between the active tropical cyclone seasons over the Arabian Sea and Bay of Bengal. Int J Climatol 39:5486-5502

72. Schott FA, McCreary JPJ (2001) The monsoon circulation of the Indian Ocean., 51(1), 1-123. doi:10.1016/s0079-6611(01)00083-0

73. Seneviratne SI, Nicholls N, Easterling D, Goodess CM, Kanae S, Kossin J, Luo Y, Marengo J, Mclnnes K, 700 Rahimi M, Reichstein M, Sorteberg A, Vera C, Zhang X (2012) Changes in climate extremes and their impacts on the natural physical environment, in Managing the Risks of Extreme Events and Disasters to Advance Climate Change Adaptation pp 109-230, Cambridge University Press, Cambridge

74. Shlens J (2014) A tutorial on principal component analysis. arXiv preprint arXiv:1404.1100

75. Siddique MAB, Khan R, Islam ARMT et al (2021) Quality assessment of freshwaters from a coastal city of southern Bangladesh: Irrigation feasibility and preliminary health risks appraisal.

Environmental Nanotechnology Monitoring Management 16:100512. doi:10.1016/j.enmm.2021.100524

76. Sielecki A and Wurtele MG (1970). The numerical integration of the nonlinear shallow-water equations with sloping boundaries. J Comput Physics, 6: 219-236

77. Singh KS, Bhaskaran PK (2019) Prediction of landfalling Bay of Bengal cyclones during 2013 using the high resolution WRF model. Meteorol Appl. https://doi.org/10.1002/met.1850

78. Singh R, Kishtawal CM, Pal PK, Joshi PC (2012) Improved tropical cyclone forecasts over NIO with direct assimilation of AMSU-A radiances. Meteorog Atmos Phys 115:15-34

79. Spada G (2017) Glacial isostatic adjustment and contemporary sea level rise: an overview. Surv Geophys 38(1):153-185. https://doi.org/10.1007/s1071 2-016-9379-x

80. Sun D, Xue F, Zhou T (2013) Impacts of two types of El Niño on atmospheric circulation in the Southern Hemisphere. Adv Atmos Sci 30:1732. https://doi.org/10.1007/s00376-013-2287-9

81. Tait AB, Fitzharris BB (1998). Relationship between New Zealand rainfall and

82. Tan PN, Steinbach M, Kumar V (2013) Data mining cluster analysis: Basic concepts and algorithms 83. The World Factbook, CIA. (2011). ISSN: 1553-8133 
84. Tasnuva A, Hossain R, Salam R, Islam ARMT et al. (2020). Employing social vulnerability index to assess household social vulnerability of natural hazards: An evidence from southwest coastal Bangladesh, Environment, Development and Sustainability, DOl: 10.1007/s10668-020-01054-9

85. Viner D (2000) Modelling Climate Change. Climatic Research Unit. United Kingdom

86. Vissa NK, Satyanarayana ANV, Prasad Kumar B (2013) Intensity of tropical cyclones during pre- and post-monsoon seasons in relation to accumulated tropical cyclone heat potential over Bay of Bengal. Nat Hazards 68:351-371

87. Wahiduzzaman M, Oliver E, Wotherspoon S, Luo JJ (2020a) Statistical forecasting of tropical cyclones over the North Indian Ocean and the role of El Ni.o-Southern Oscillation. Clim Dyn 54(23):1571-1589

88. Wahiduzaman M, Islam ARMT, Luo J, Shahid S, Uddin MJ, Shimul SM, Sattar MA (2020b) Trends and variabilities of thunderstorm days over Bangladesh on the ENSO and IOD timescales. Atmosphere 11(11):1176. doi:10.3390/atmos11111176

89. Wahiduzzaman M, Yeasmin A, Luo J-J, Quadir DA, Van Amstel A, Cheung K, Yuan C (2021a) Markov Chain Monte Carlo simulation and regression approach guided by El Niño-Southern Oscillation to model the tropical cyclone occurrence over the Bay of Bengal. Clim Dyn 56(9-10):2693-2713. doi:10.1007/s00382-020-05610

90. Wahiduzzaman M, Cheung K, Luo JJ, Bhaskaran PK, Tang S, Yuan C (2021b) Impact assessment of Indian Ocean Dipole on the North Indian Ocean tropical cyclone prediction using a Statistical model. Clim Dyn. doi. 10.1007/s00382-021-05960-0

91. Wahiduzzaman M, Yeasmin A (2019) Statistical forecasting of tropical cyclone landfall activities over the North Indian Ocean rim. Atmos Res 227:89-100

92. Wahiduzzaman M, Oliver ECJ, Wotherspoon SJ, Holbrook NJ (2017) A climatological model of North Indian Ocean tropical cyclone genesis, tracks and landfall. Clim Dyn 49:2585-2603

93. WARPO (2006) Coastal development strategy, water resources planning organization (WARPO). Dhaka. Ministry of Water Resources, Government of the People's Republic of Bangladesh, Bangladesh

94. Webster PJ (2008). Myanmar's deadly daffodil. Nat. Geosci. 1, 488-490 Wahiduzzaman M, Yeasmin A, 2019a. Statistical forecasting of tropical cyclone landfall activities over the North Indian Ocean rim countries. Atmos. Res. 227, 89-100

95. Weinkle J, Maue R, Pielke R (2012) Historical global tropical cyclone landfalls. J Clim 25:4729-4735 96. Yarnal B (1993) Synoptic Climatology in Environmental Analysis. Belhaven Press, London

97. Yeater KM, Duke SE, Riedell WE (2015) Multivariate analysis: Greater insights into complex systems. Agron J 107(2):799-810

98. Zhou Y, Matyas C, Li H, Tang J (2018) Conditions associated with rain field size for tropical cyclones landfalling over the Eastern United States. Atmos Res 214:375-385 
Figures

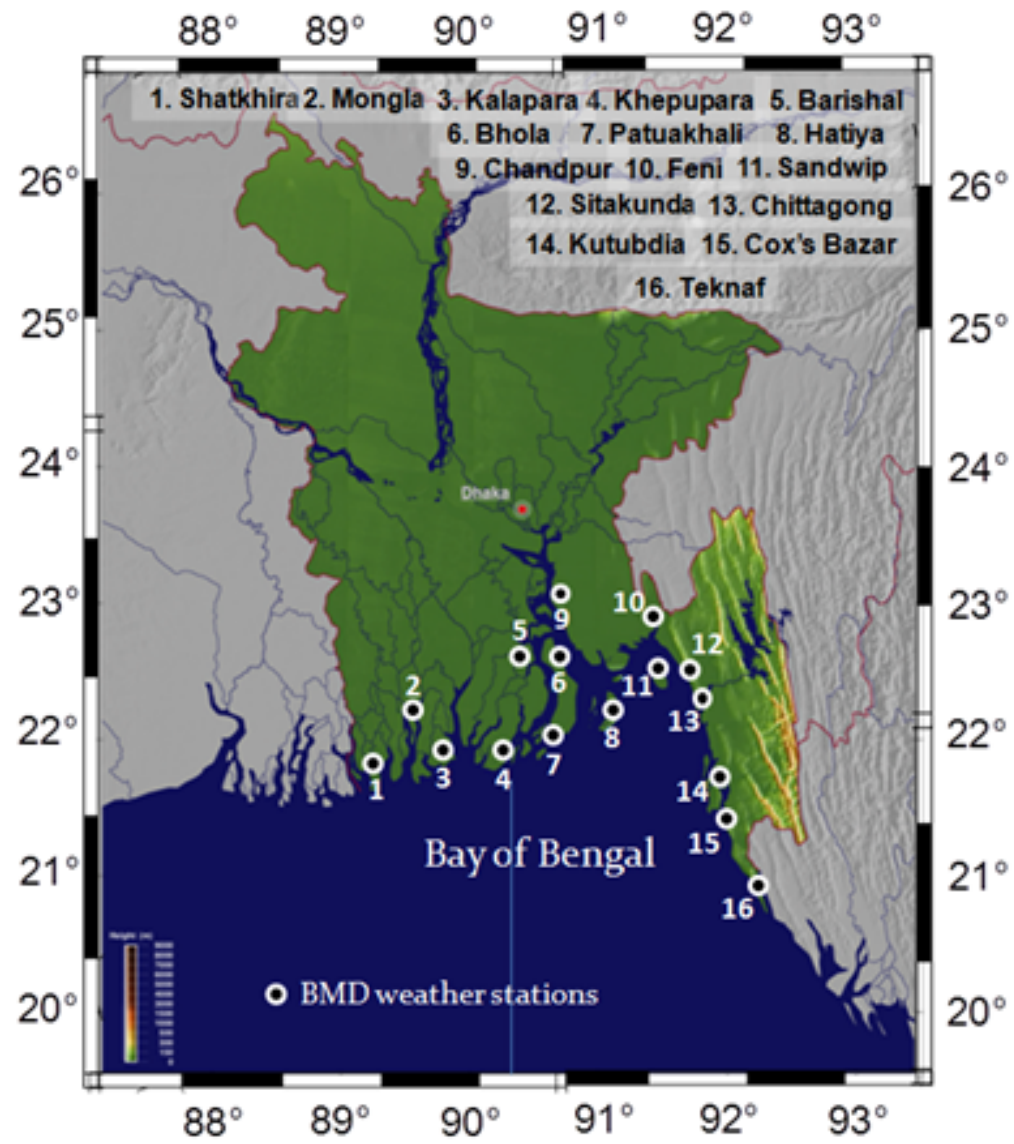

Figure 1

Study sites showing the southern coastal region of Bangladesh. 


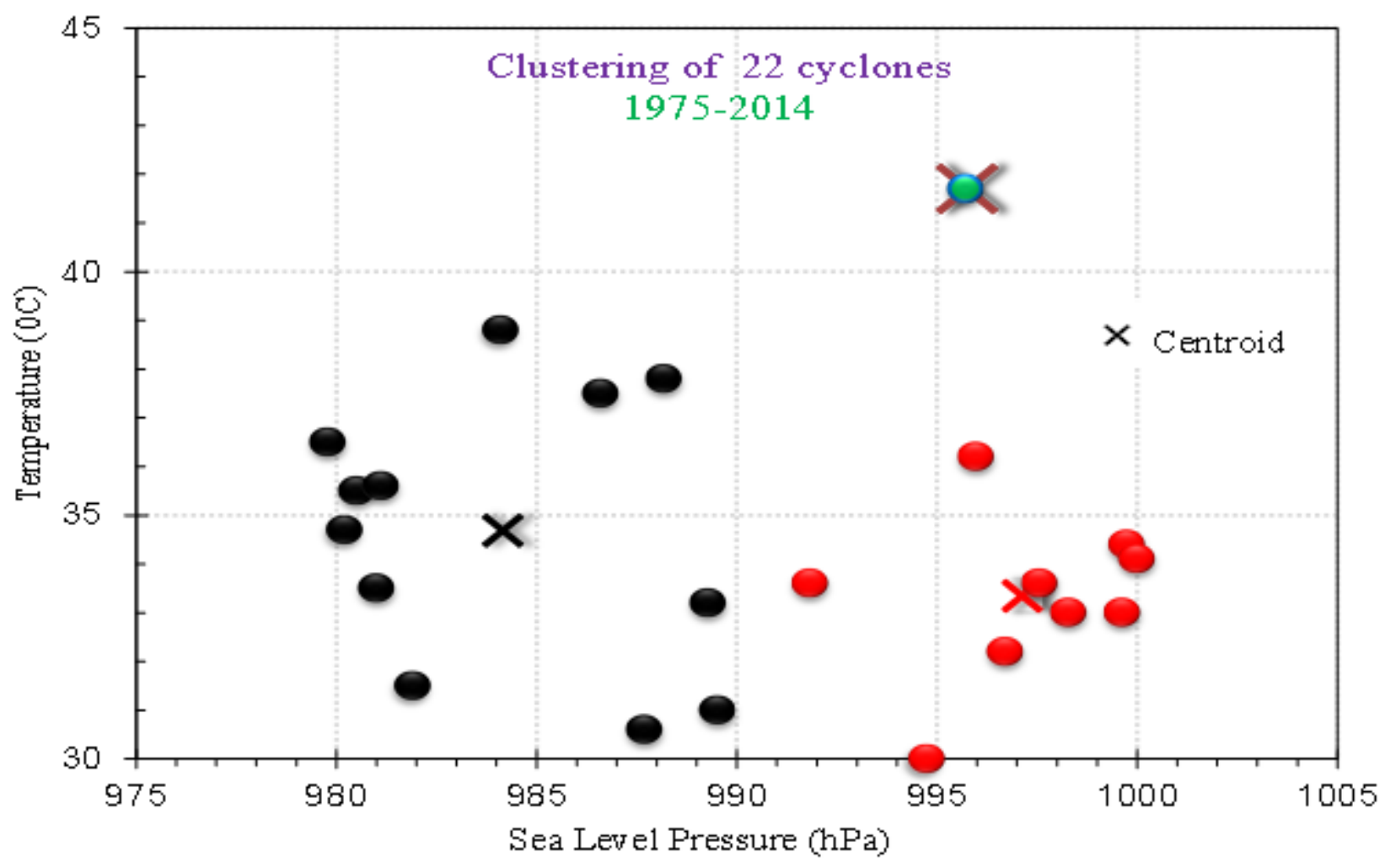

Figure 2

Clustering of 22 TCs from 1975-2014 in 3 clusters 

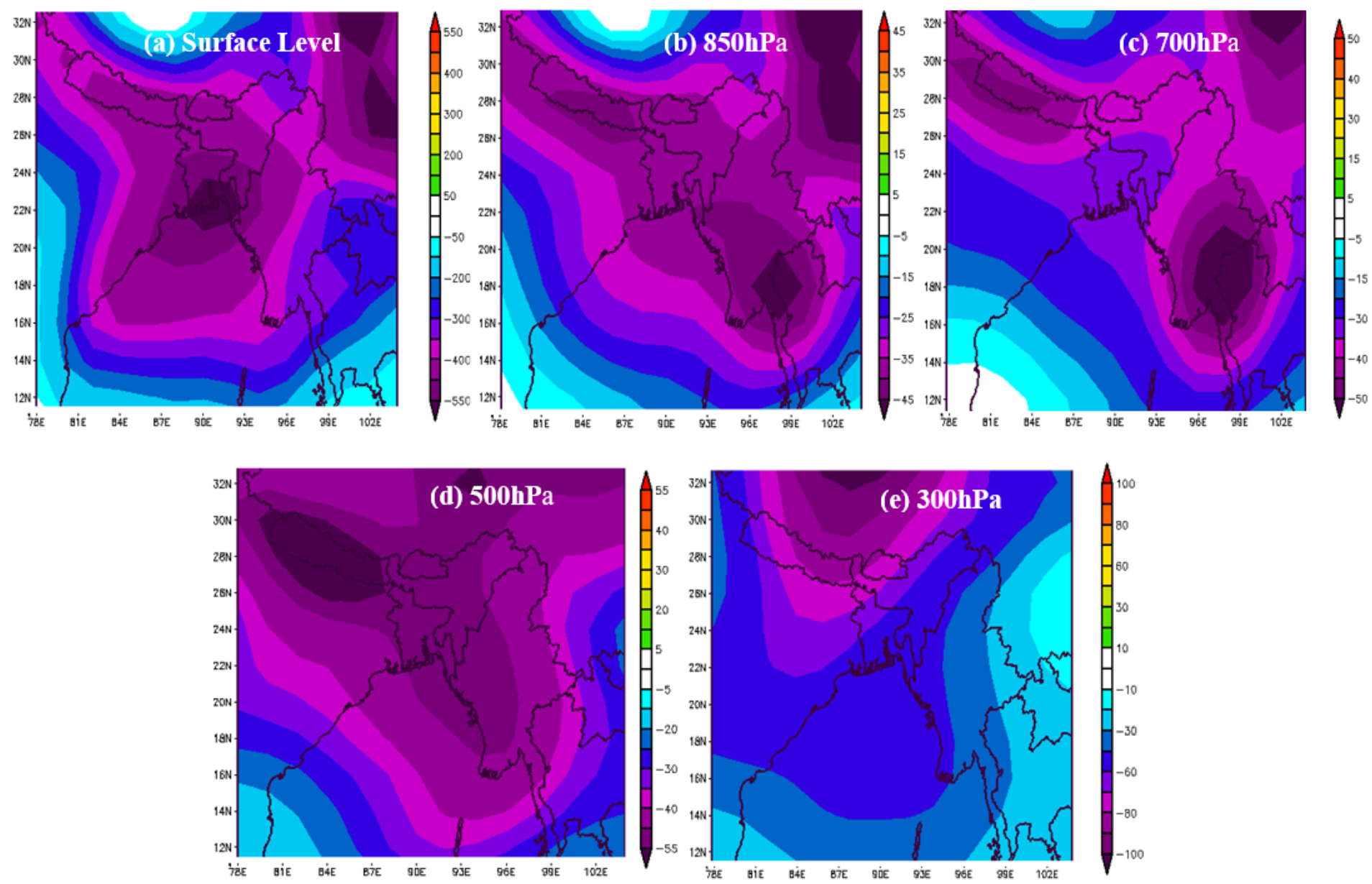

Figure 3

(a) SLP (Pa) at surface level (b) SLP at $850 \mathrm{hPa}$ level (c) SLP at $700 \mathrm{hPa}$ level (d) SLP at 500hPa level and (e) SLP at $300 \mathrm{hPa}$ level for cluster 1 

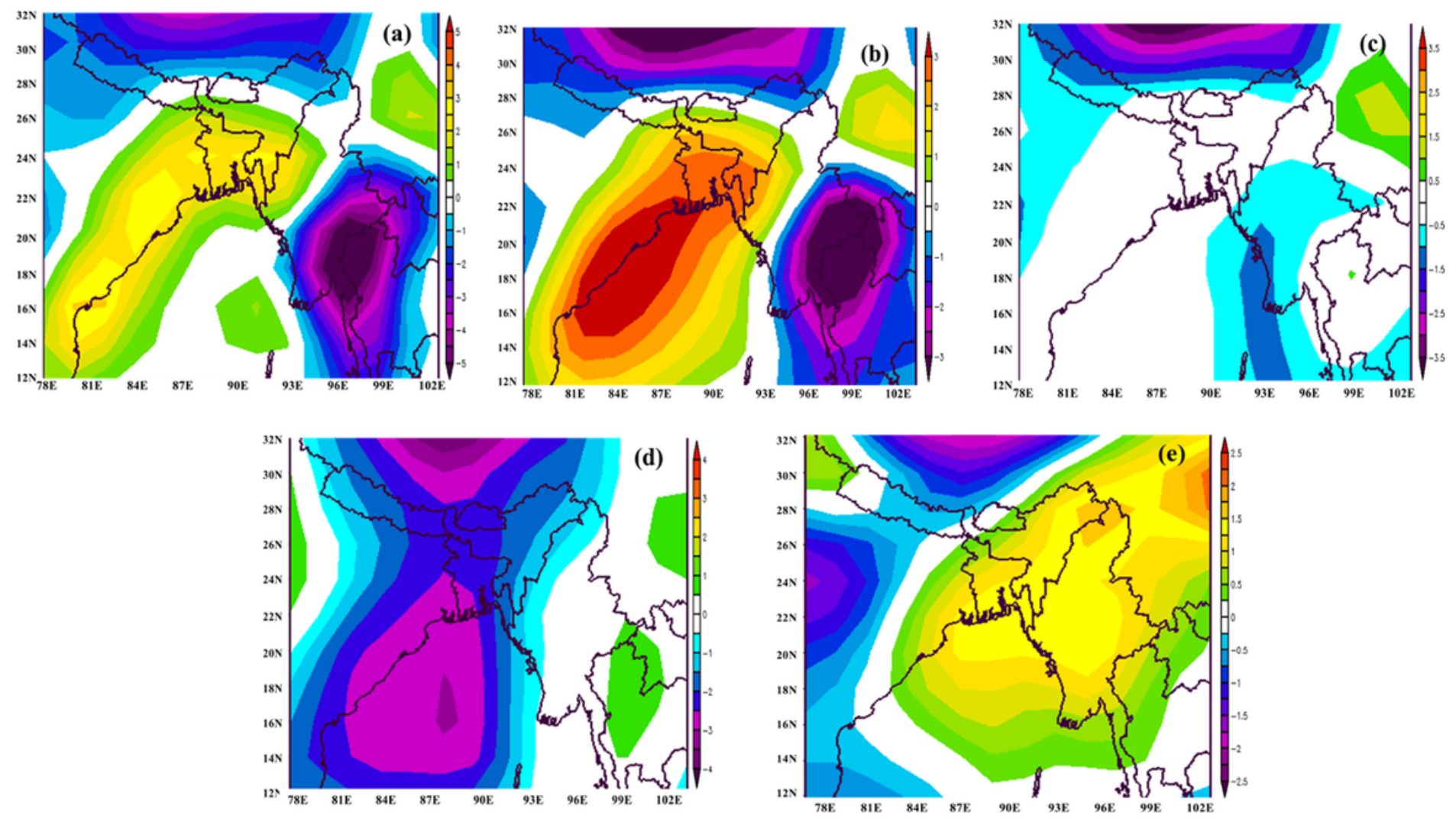

Figure 4

The patterns of composite air temperature $\left({ }^{\circ} \mathrm{C}\right)$ anomaly for cluster 1 compared with 1975-2014 climatology for a passing day of cyclone at (a) surface level (b) $850 \mathrm{hPa}$ level (c) $700 \mathrm{hPa}$ level (d) $500 \mathrm{hPa}$ level and (e) 300hPa level. 

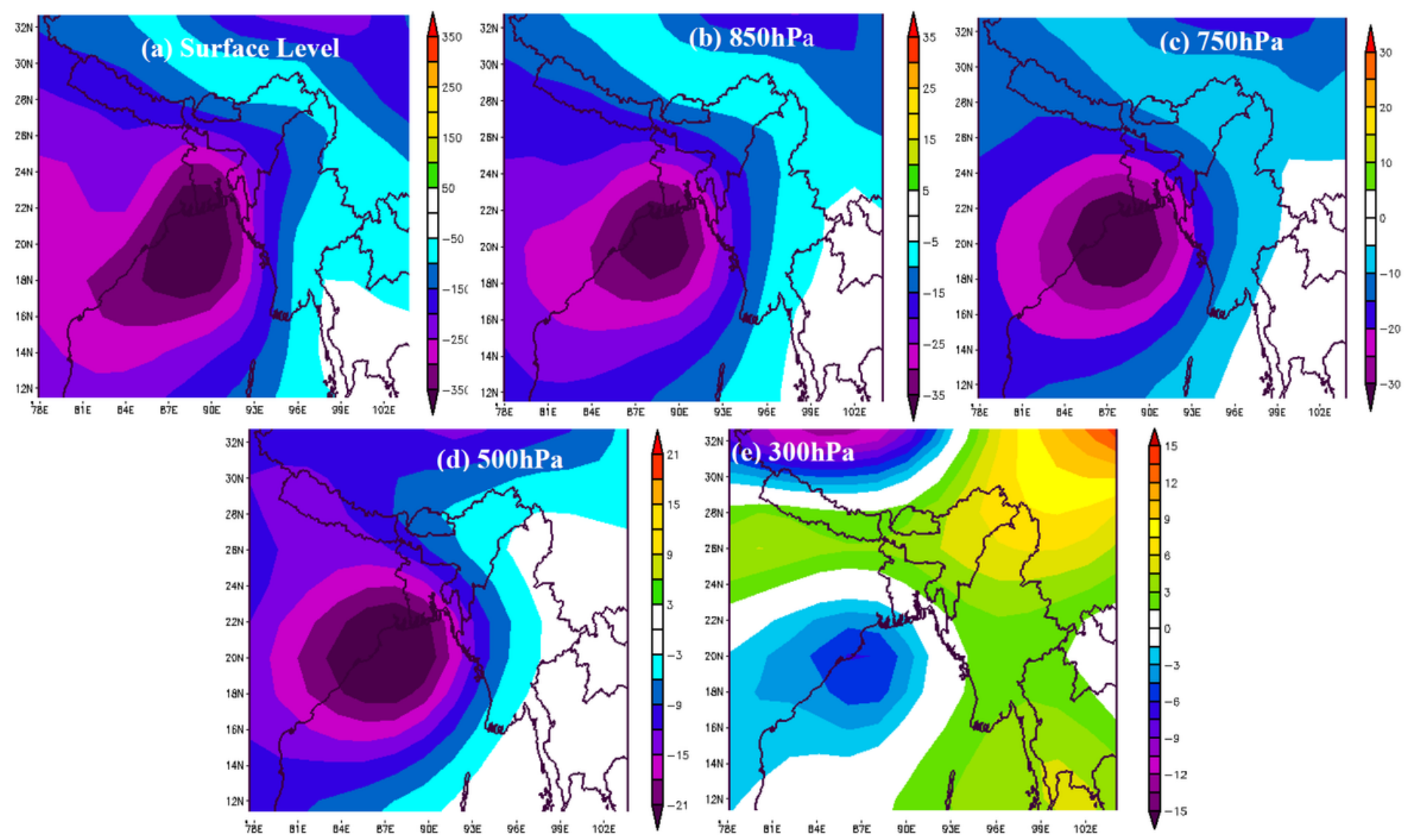

Figure 5

(a) SLP (Pa) at surface level (b) SLP at $850 \mathrm{hPa}$ level (c) SLP at $700 \mathrm{hPa}$ level (d) SLP at 500hPa level and (e) SLP at $300 \mathrm{hPa}$ level for cluster 2 

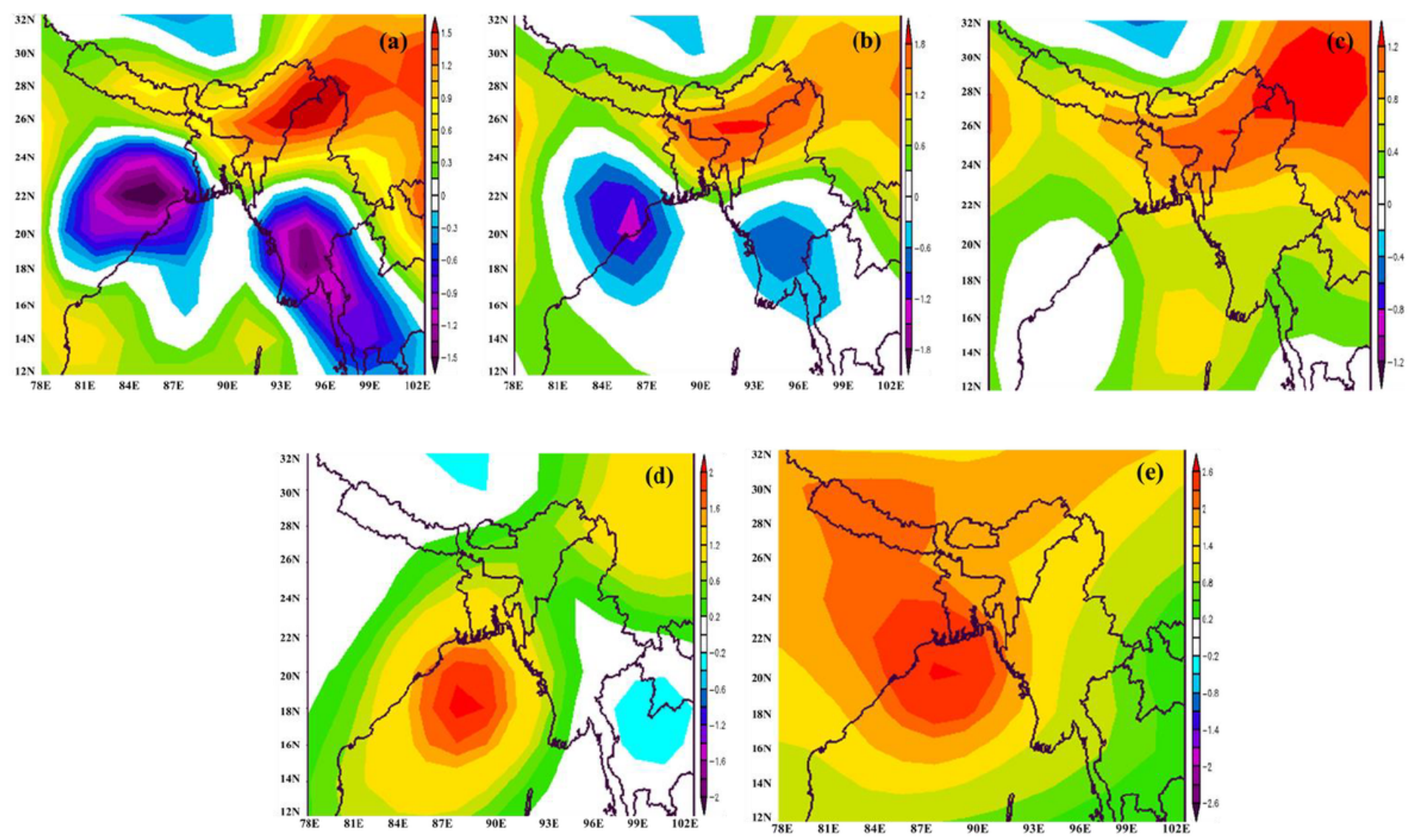

Figure 6

The patterns of composite air temperature $\left({ }^{\circ} \mathrm{K}\right)$ anomaly for cluster 2 compared with 1975-2014 climatology for the passing days of cyclones at (a) surface level (b) $850 \mathrm{hPa}$ level (c) 700hPa level (d) $500 \mathrm{hPa}$ level and (e) $300 \mathrm{hPa}$ level 

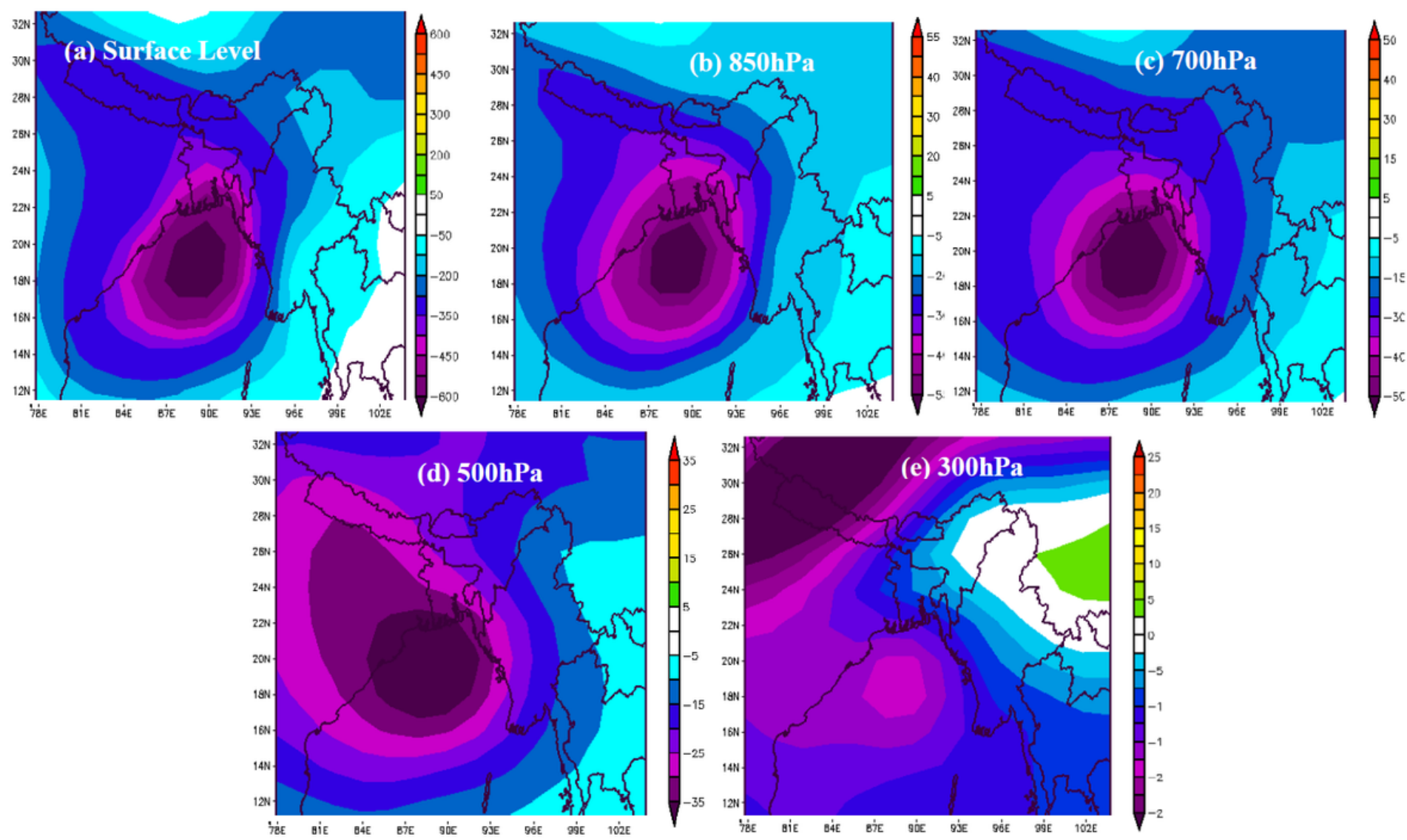

\section{Figure 7}

(a) SLP (Pa) at surface level (b) SLP at $850 \mathrm{hPa}$ level (c) SLP at $700 \mathrm{hPa}$ level (d) SLP at 500hPa level and (e) SLP at $300 \mathrm{hPa}$ level for cluster 3

展

\section{Figure 8}

The composite air temperature $\left({ }^{\circ} \mathrm{C}\right.$ ) anomaly for cluster 3 at (a) surface level (b) $850 \mathrm{hPa}$ level (c) $700 \mathrm{hPa}$ level (d) 500hPa level and (e) 300hPa level

\section{Supplementary Files}

This is a list of supplementary files associated with this preprint. Click to download.

- SupplementaryDocs.10022021.docx 